\title{
FISSURAÇÃO EM TRAVESSA DE APOIO DE LONGARINAS DE PONTES
}

\author{
THOMAZ, EDUARDO CHRISTO SILVEIRA \\ Professor Emérito \\ Instituto Militar de Engenharia \\ Rio de Janeiro; Brasil \\ ecsthomaz@terra.com.br
}

\author{
CARNEIRO, LUIZ ANTONIO VIEIRA \\ Professor Adjunto \\ Universidade Federal Fluminense \\ Rio de Janeiro; Brasil \\ luizcarneiro@id.uff.br
}

\author{
PERLINGEIRO, MAYRA SOARES PEREIRA LIMA \\ Professora Associada \\ Universidade Federal Fluminense \\ Rio de Janeiro; Brasil \\ mayraperlingeiro@id.uff.br
}

\section{RESUMO}

Este trabalho teve por objetivo apresentar alguns casos de fissuração do concreto em travessa de apoio de pontes em concreto. São comentados seis casos ocorridos em pontes de concreto, onde se relatam os problemas encontrados, as causas da fissuração e as possíveis soluções para estes casos. Há causas de fissuração do concreto relacionadas à corrosão das armaduras internas pela entrada de agentes agressivos no concreto ou pela corrente elétrica de fuga, e ao recalque de apoio das travessas. Verificou-se neste trabalho que a maioria das causas de fissuração se deve a falhas na execução e no projeto, detalhamento e dimensionamento desta travessa de apoio.

Palavras-chave: casos, fissuração, concreto, pontes.

\section{ABSTRACT}

This work aims at presenting some cases of concrete cracking in beam deck of concrete bridges. Six cases from concrete bridges are reported and its problems encountered, causes of cracking and possible solutions are discussed. There are causes of concrete cracking related to internal reinforcement corrosion by the entry of aggressive agents into the concrete or by leakage electrical current, and to settlement support of beam deck. It was found in this study that most causes of cracking is due to failures in construction phase and in design and detailing of this beam deck.

Keywords: cases, cracking, concrete, bridges.

\section{INTRODUÇÃO}

Em estruturas de concreto que apresentem manifestações patológicas, deve-se inicialmente fazer uma inspeção visual, com o objetivo de se identificar a origem das ações, os tipos de solicitações principais decorrentes destas ações, as causas e a extensão dos danos.

Os sintomas apresentados pela estrutura danificada devem ser observados para a correta identificação das causas dos danos. Faz-se, então, uma avaliação do estado atual da segurança da estrutura e, dependendo do resultado, intervém-se imediatamente ou não.

Os materiais da estrutura danificada são investigados, consultando-se o projeto original, caso disponível, ou coletandose amostras para ensaios de campo e de laboratório. As deformações das armaduras internas podem ser avaliadas por meio da abertura máxima e do espaçamento das fissuras, visando a verificar se é possível contar ou não com as armaduras existentes no projeto de reparo e/ou reforço.

A seguir, elabora-se um estudo de viabilidade técnico-econômica, sendo decidido o tipo de reparo e/ou reforço a empregar, conciliando-se a técnica mais eficiente, o custo total e as condições de execução. Caso o estudo elaborado não seja favorável, parte-se para a demolição da estrutura ou de parte dela para futura reconstrução, se possível, ou retiram-se sobrecargas atuantes, submetendo a peça estrutural a situações menos adversas (CARNEIRO, 1998). 
Finalmente, executam-se o projeto e o detalhamento da técnica mais apropriada de reparo e/ou reforço, com especial atenção ao controle de qualidade do projeto, da execução e dos materiais a empregar.

Neste trabalho apresentam-se os problemas encontrados, as causas da fissuração do concreto e as possíveis soluções para estes problemas em travessas de apoio de pontes em concreto. Há causas de fissuração do concreto relacionadas à corrosão das armaduras internas pela entrada de agentes agressivos no concreto ou pela corrente elétrica de fuga, e ao recalque de apoio das travessas.

\section{TRAVESSA}

A travessa é um elemento estrutural pertencente à mesoestrutura de pontes, cuja principal função é de receber as cargas provenientes da superestrutura e transmiti-las para os pilares.

Há alguns tipos de configurações de travessas: pilar único com travessa, pilar duplo ou mais pilares com travessa. A Figura 1 ilustra as travessas mais usuais, que também são denominadas de viga-travessa, pois se trata de uma viga larga, podendo ter recorte ou não, onde as longarinas se apoiam. Seu comprimento é um pouco maior que a largura do tabuleiro. A altura pode ser constante ou variável, com formato retangular ou seção "T" invertida.

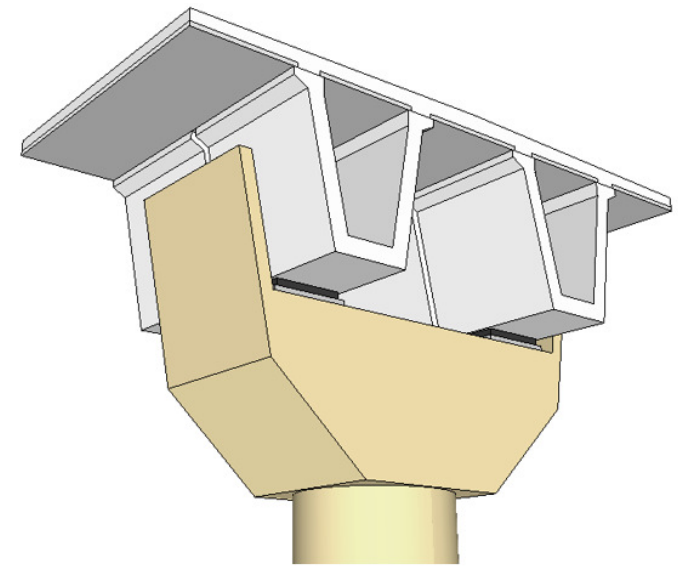

(a) Pilar circular com travessa trapezoidal

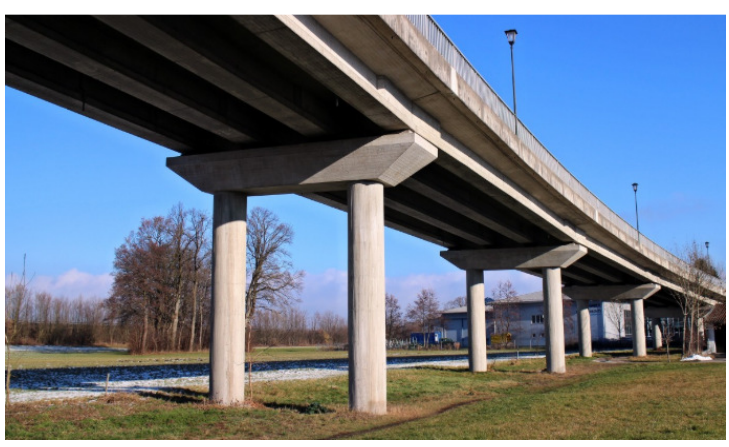

(c) Pilar circular com travessa trapezoidal

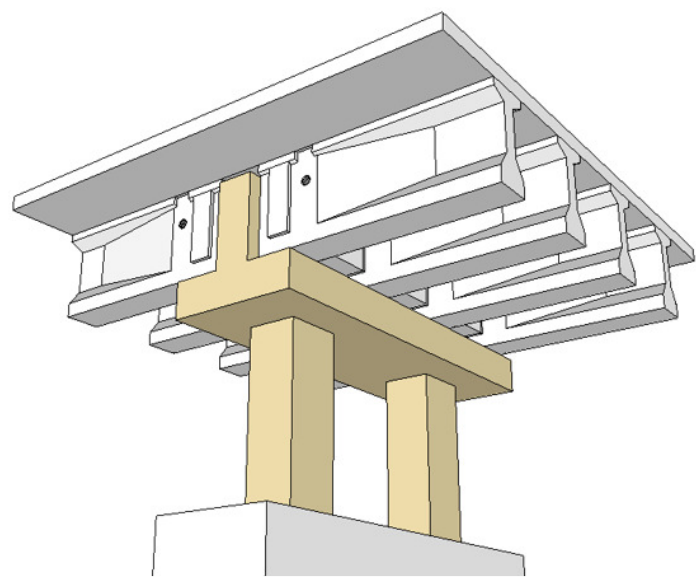

(b) Dois pilares com travessa em " $T$ " invertido

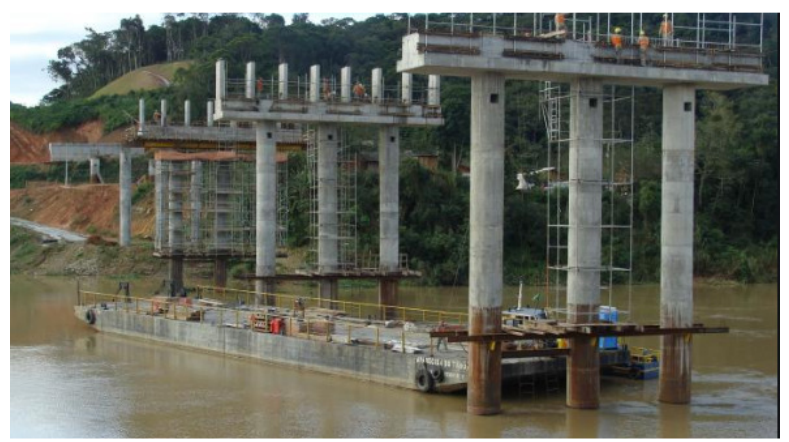

(d) Três pilares com travessa em "T" invertido

Figura 1: Tipos de travessa de pontes

Os esforços atuantes verticais nas travessas são decorrentes das reações da ação de peso próprio dos elementos estruturais da superestrutura (laje, longarinas e transversinas), da sobrecarga permanente (pavimentação, barreiras, iluminação, entre outras) e das sobrecargas acidentais que são consequência da ação da carga móvel sobre o tabuleiro.

Também ocorrem nas travessas as ações horizontais em função do tráfego da carga móvel sobre a laje da estrutura, onde a frenagem e a aceleração formam os esforços preponderantes nesta direção. 
O pré-dimensionamento da seção do engaste é feito considerando-se os esforços combinados no Estado Limite Último. Travessa em pilar único deve ser dimensionada a partir do modelo de cálculo de uma viga engastada no pilar e livre na extremidade.

\section{MANIFESTAÇÕES PATOLÓGICAS}

Diversas são as causas de manifestações patolóticas em estruturas de concreto, que podem estar relacionadas à deterioração dos materiais, aos erros de origem humana e aos acidentes (APPLETON e SOUZA, 1986).

O envelhecimento natural, os ataques químicos (cloretos, sais, ácidos e sulfatos) e biológicos (raízes, fungos e esgotos), a má utilização e a falta de manutenção requerida nas estruturas são algumas das causas de deterioração relacionadas aos materiais.

Os erros de origem humana podem ser atribuídos à má concepção, detalhes e projeto incompletos e modelos de análise e de cálculo incorretos, à falta de qualificação técnica na execução e à inadequada seleção dos materiais.

Os acidentes podem ser de origem natural, tais como sismos, cheias, deslizamentos de terras, entre outros, ou de origem humana, como incêndios, explosões, choques, inundações, e outros.

A fissuração do concreto é a manifestação patológica mais comum nas estruturas de concreto, por conta dos efeitos reológicos, que são as modificações internas de comportamento do concreto ao longo do tempo, da composição do concreto ou das solicitações aplicadas nas estruturas de concreto.

As fissuras decorrentes de cargas diretas em estruturas de concreto são originadas por tensões de tração provocadas por solicitações de flexão, cisalhamento, punção, torção, alguns casos de protensão, entre outros (CARMONA FILHO e CARMONA, 2013).

Por apresentar baixa resistência à tração, caso alguma tensão de solicitação interna ultrapasse esta resistência, o concreto fissura, cuja abertura depende de diferentes parâmetros, tais como a bitola, o coeficiente de conformação superficial e a deformação da armadura interna, entre outros.

As fissuras decorrentes de outros fenômenos, isto é, aqueles não relacionados a cargas diretas em estruturas de concreto, podem ser motivadas por assentamento plástico, movimentação de formas, retração do concreto, variação de temperatura, deslocamentos impostos - recalques diferenciais de fundação, e por fenômenos químicos deletérios, tais como ataque de sulfatos, reação álcali-agregados, corrosão das armaduras (CARMONA FILHO e CARMONA, 2013).

Segundo a norma NBR 6118 (ABNT, 2014), a fim de cumprir as exigências de durabilidade relacionadas à fissuração em função da classe de agressividade ambiental, as estruturas de concreto armado podem apresentar fissuras com abertura entre $0,2 \mathrm{~mm}$ e $0,4 \mathrm{~mm}$ no estado limite de abertura de fissuras para combinação de ações frequente em serviço, enquanto as estruturas de concreto protendido, abertura de até 0,2 $\mathrm{mm}$ em caso de protensão parcial.

Os títulos dos subitens a seguir estão associados à manifestação patológica encontrada por THOMAZ (2017) em diferentes travessas de apoio de pontes em concreto armado ou protendido.

\subsection{Fissuras verticais e inclinadas}

A Figura 2 ilustra uma travessa de apoio em concreto de longarinas pré-moldadas, onde há fissuração generalizada de flexão e de cisalhamento em todos os vãos e apoios.

Existem várias fissuras verticais e inclinadas, nas faces inferior e faces laterais, tanto nos vãos como sobre o apoio intermediário (bordo superior). Essas fissuras foram originárias de possível excesso de carga do tráfego atual sobre as travessas e/ou de provável deficiência na análise estrutural inicial.

O aspecto visual da fissuração foi agravado pela recuperação feita, que contemplou a colocação de massa epoxídica com $20 \mathrm{~mm}$ a $40 \mathrm{~mm}$ de largura em fissuras que tinham cerca de $0,30 \mathrm{~mm}$ de abertura. 


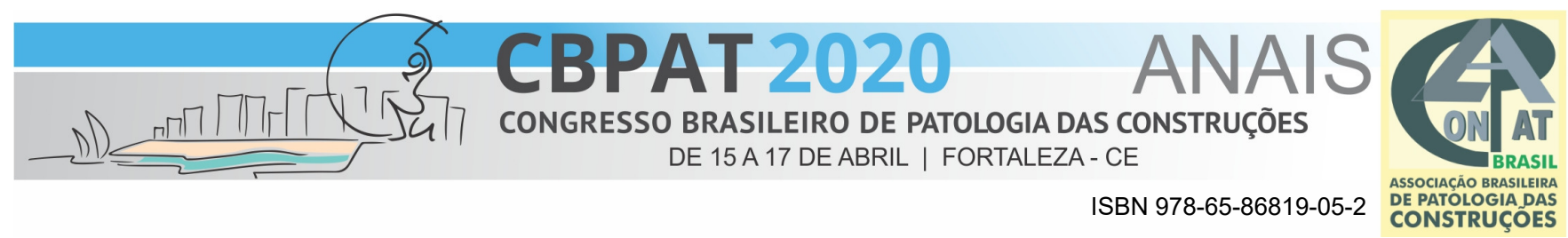

Certamente a estrutura esteve próxima do estado de "fissuração consolidada", isto é, já tinham se formadas todas as fissuras. Com um futuro aumento de carga de tráfego, as fissuras já existentes tendem a ter sua abertura aumentada.

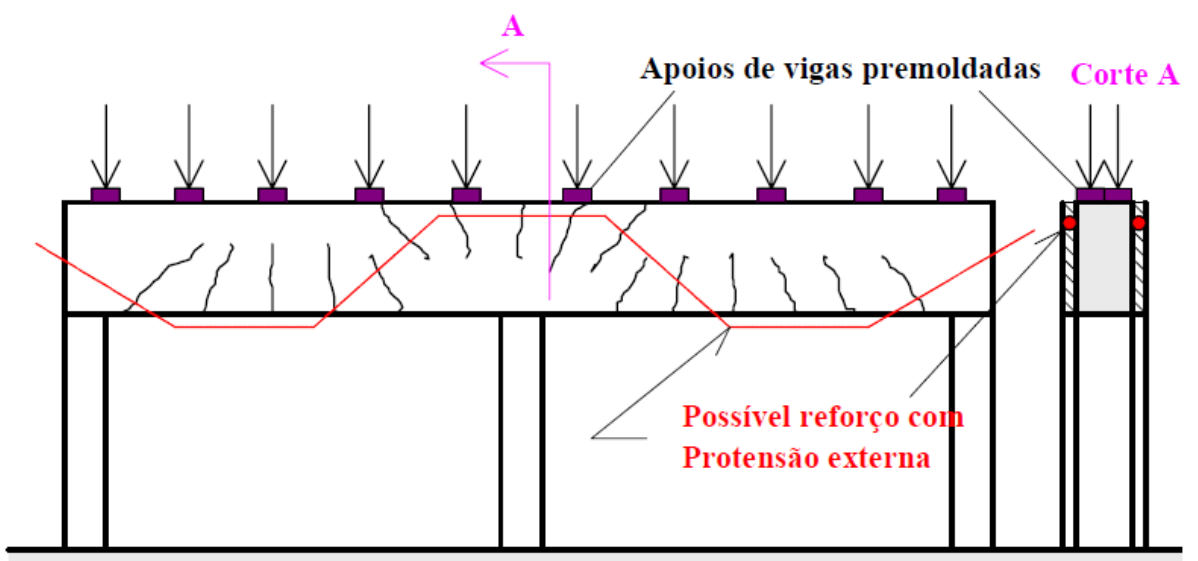

Figura 2: Travessa de apoio de longarinas premoldadas com fissuras verticais e inclinadas

Isso sugere que o comportamento global da estrutura deve ser verificado, avaliando-se a segurança estrutural para cargas de tráfego mais compatíveis com os veículos atuais. Uma protensão externa de modo a reforçar a estrutura se faz necessário, como indicado na Figura 2.

Ressalta-se que, mesmo antes de serem implementadas as medidas de reforço necessárias, deve-se manter a observação permanente da estrutura para detectar eventuais surgimentos de novas fissuras ou o aumento da abertura das fissuras já existentes.

\subsection{Fissuras em malha}

Uma travessa em concreto armado servindo de apoio a longarinas, apresentando fissuras verticais e horizontais em formato de malha, pode ser visualizada na Figura 3.
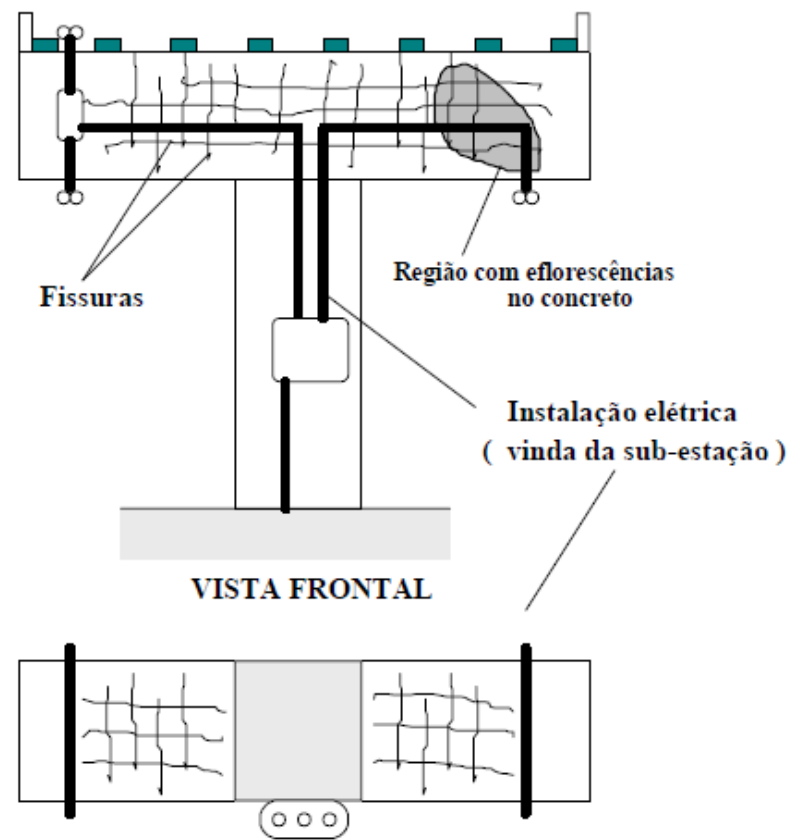

PLANTA

Figura 3: Travessa de apoio de longarinas com fissuras em malha 
Como se vê na Figura 3, existem várias fissuras já injetadas nas duas faces laterais da travessa e principalmente na face inferior da travessa.

Provavelmente, estas fissuras foram causadas pela corrosão das armaduras de pele (estribos e costelas). A corrosão destas armaduras, em duas travessas que suportam cabos elétricos para sinais de trânsito (sinalização) e para iluminação da obra, foi mais acentuada que nas demais, levantando a hipótese de que correntes elétricas foram induzidas nas armaduras, acelerando o processo de corrosão elétrolítica. Essas duas travessas vizinhas estão próximas a uma subestação elétrica, sendo necessário identificar se essa é realmente a causa.

Como solução, sugere-se fazer injeção nas fissuras ainda não tratadas considerando que estas fissuras não apresentam movimento. Seria justificável instrumentar as armaduras para detectar possíveis correntes elétricas.

\subsection{Fissuras verticais}

A Figura 4 mostra uma travessa de apoio de longarinas premoldadas, onde em apenas uma face da travessa existem fissuras praticamente verticais a meia altura sobre os apoios e fissuras verticais no vão.

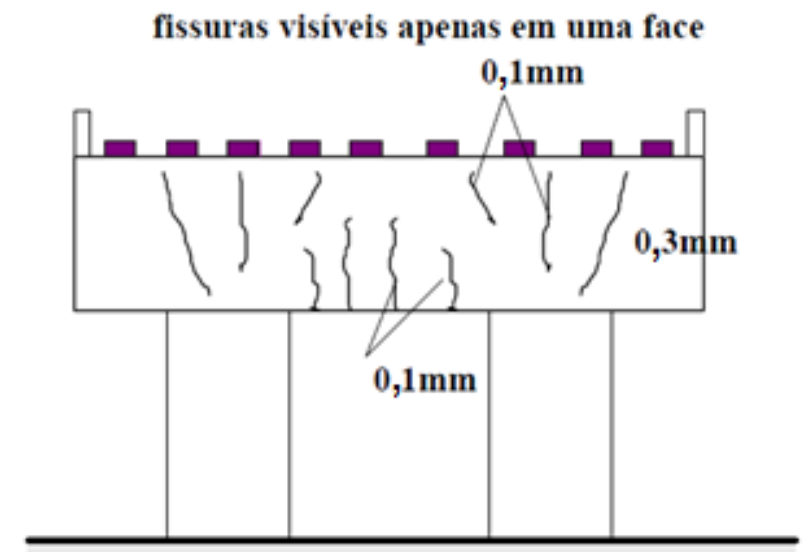

Figura 4: Travessa de apoio de longarinas premoldadas com fissuras verticais

Na travessa de apoio da Figura 4, há várias fissuras já injetadas em apenas uma das faces da travessa e principalmente na face inferior da travessa, causadas possivelmente por problemas de execução da peça.

Os estribos da travessa em uma de suas faces parecem ter sido colocados com pouco cobrimento de concreto e, em consequência na outra face da travessa, o cobrimento de concreto ficou grande e não ocorreram fissuras, pois não houve corrosão nem dos estribos nem das barras de aço de costela (barras horizontais). Também na face inferior a fissuração do concreto sugere que os estribos foram colocados sem cobrimento de concreto adequado, o que levou à corrosão das barras de aço e, por conseqüência, à fissuração do concreto.

Nas fissuras ainda não tratadas, recomendou-se seguir o procedimento usual para injeção de fissuras sem movimento. A solução ideal nesses casos seria sempre uma obra com execução cuidadosa em todos os detalhes, com especial atenção ao cobrimento e cura do concreto, o que sempre evita reparos à frente.

\subsection{Fissuras inclinadas}

Fissuras inclinadas em ambas as faces de uma travessa de apoio de longarinas premoldadas podem ser vistas na Figura 5 .

A causa provável dessas fissuras parece ser um pequeno recalque da fundação do pilar à direita, P2, conforme se visualiza na Figura 5. A posição inclinada dessas fissuras caracteriza o movimento vertical para baixo do pilar P2, como sinalizado na Figura 5. 
Como as fundações são antigas, é pouco provável que este recalque esteja acontecendo agora. É possível que estando a estrutura já fissurada, a abertura dessas fissuras vá aumentando, porém com o aumento das cargas móveis que atuam na estrutura.

Como as fissuras são indicativas de um recalque de apoio e como este recalque já deve ter ocorrido na sua totalidade, após confirmação por meio de acompanhamento topográfico, deve-se seguir o procedimento usual para injeção de fissuras sem movimento.

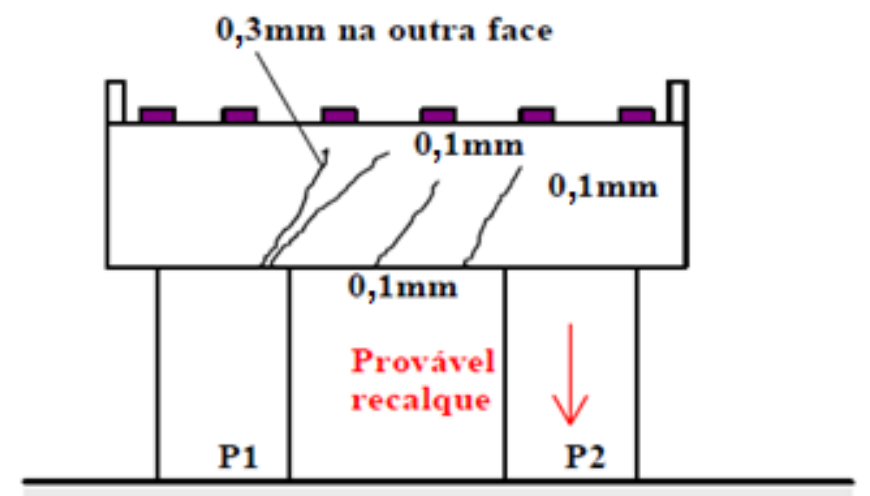

Figura 5: Travessa de apoio de longarinas premoldadas com fissuras inclinadas

\subsection{Fissuras inclinadas próximas ao apoio}

A Figura 6 apresenta uma travessa de apoio de longarinas premoldadas com fissura inclinada, localizada próxima ao apoio central e imediatamente à direita do pilar.

A fissura inclinada no dente da travessa, à direita do pilar, é oriunda do fendilhamento da biela que leva a carga da longarina mais próxima do pilar diretamente para este pilar. O fato deveria ocorrer também com a longarina da esquerda, porém a resistencia do concreto à tração poderia ter sido ser maior nesta região e, então, o concreto não fissurou.

O engenheiro calculista suspendeu a carga da longarina atuante no dente da travessa para a parte central alta da travessa e, daí em diante, a viga foi armada de modo usual. No entanto, a estrutura não seguiu a hipótese do cálculo e a carga da longarina se dirigiu diretamente para o pilar, formando uma biela que fendilhou.

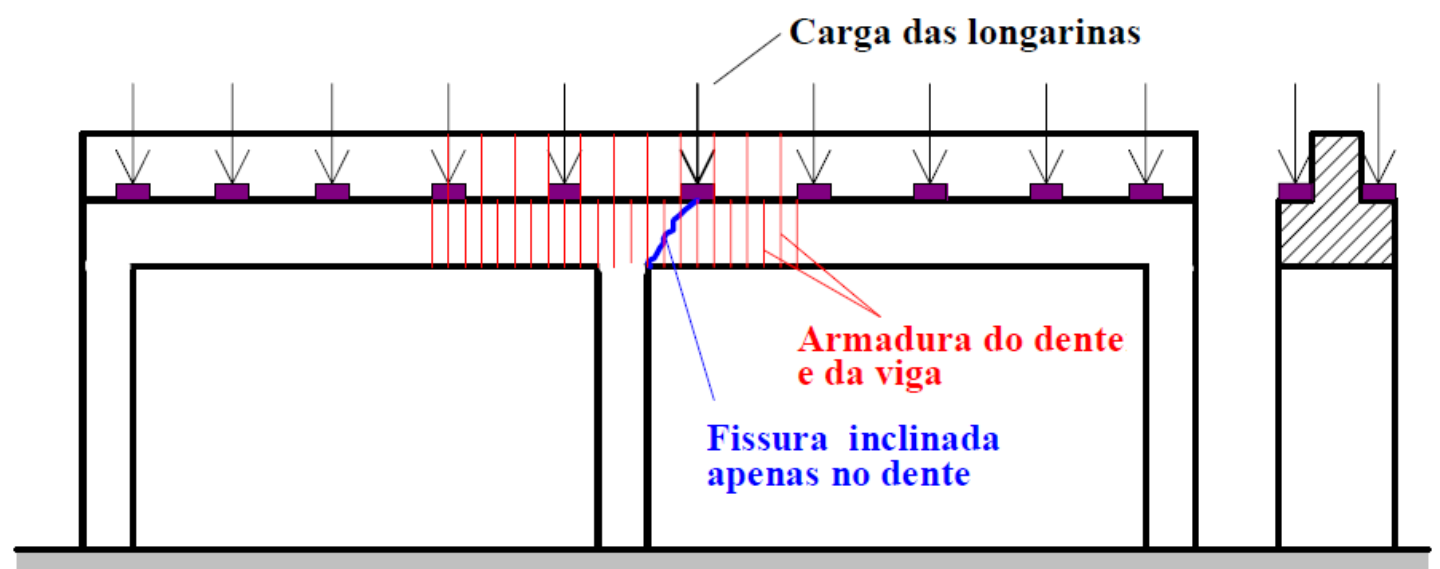

Figura 6: Travessa de apoio de longarinas premoldadas com fissuras inclinadas próximas ao apoio 
Dois pórticos em concreto armado estão ilustrados na Figura 7, onde pode-se notar o mesmo tipo de fissura por fendilhamento da biela de concreto.

Em projetos com situações semelhantes, é necessário verificar o possível fendilhamento da biela de concreto criada pela transmissão direta de carga ao apoio e, caso haja necessidade, colocar armadura de fretagem para reduzir a abertura de eventual fissura por fendilhamento do concreto.

Caso em que essa fissura já exista, deve-se verificar também se essa biela de concreto já fissurada tem suficiente segurança contra a ruptura. Se não tiver, torna-se indispensável alargar o pilar de modo a garantir a transmissão da carga diretamente a este pilar.
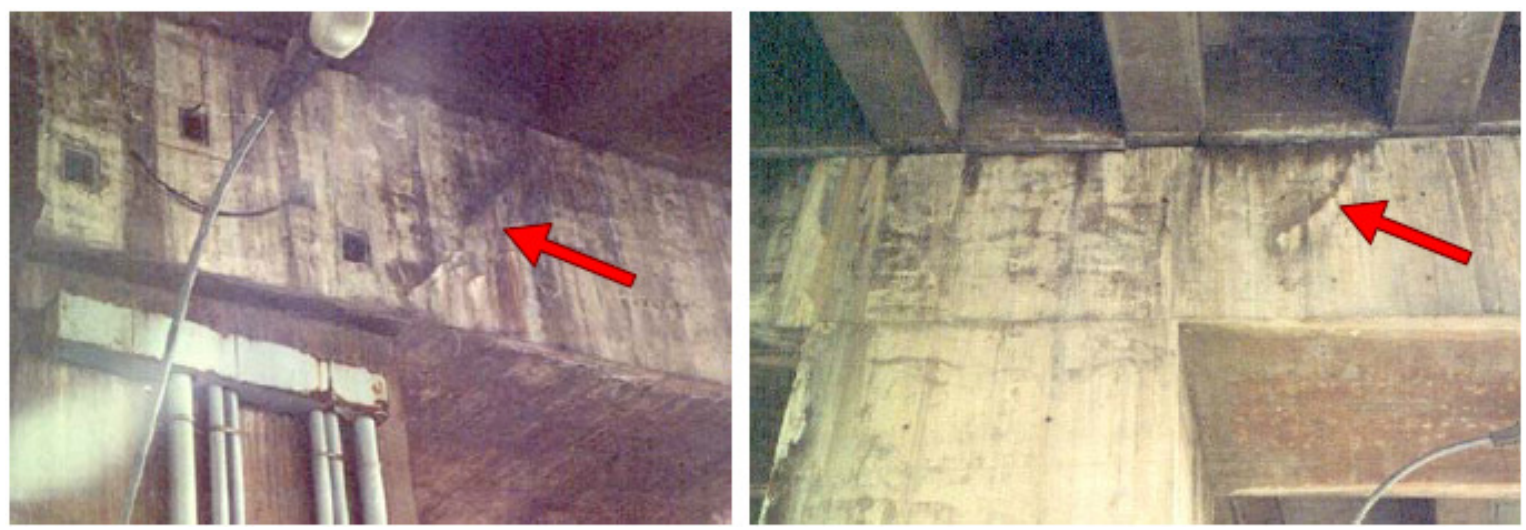

Figura 7: Dois pórticos em concreto armado com fissura inclinada próxima ao apoio

Pode ocorrer que o modelo estrutural adotado no projeto não seja o modelo que ocorre na realidade. Em caso de dúvida, a regra prática do Professor Schlaich se aplica e afirma que o modelo mais próximo da realidade é o que requer menos armadura.

\subsection{Desprendimento do cobrimento de concreto}

Uma travessa de apoio de longarinas premoldadas com desplacamento do cobrimento de concreto na região ao longo do estribo pode ser vista na Figura 8.

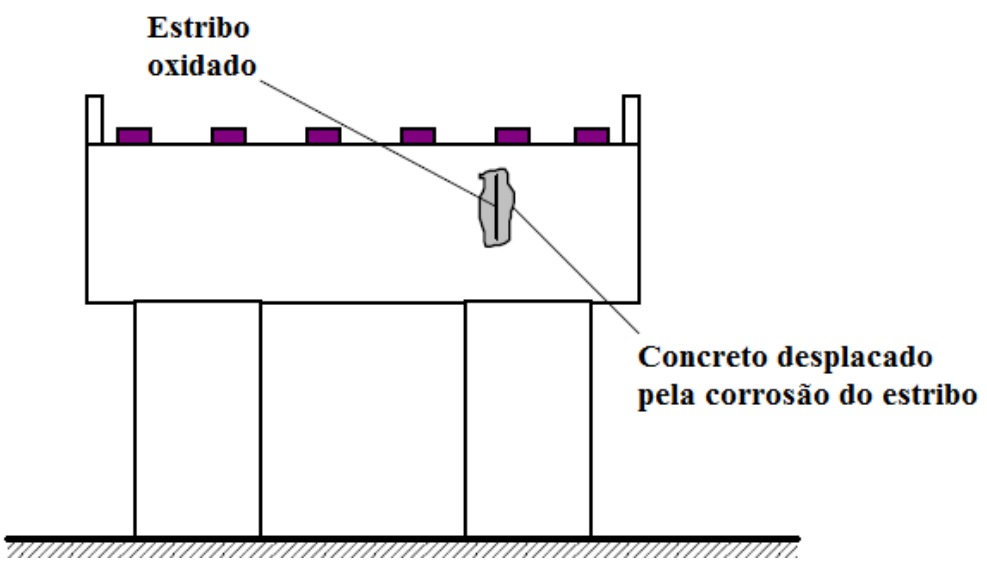

Figura 8: Travessa de apoio de longarinas premoldadas com concreto desplacado

O estribo com cobrimento de concreto pequeno sofreu corrosão, cujo produto de corrosão se expandiu e rompeu o cobrimento de concreto. É o primeiro sinal visível que uma estrutura apresenta quando já se iniciou a corrosão das barras da armadura. Embora seja um sinal muito claro, indicando que providências precisam ser tomadas para controlar a corrosão das armaduras, nem sempre esse aviso é compreendido pelo engenheiro. 


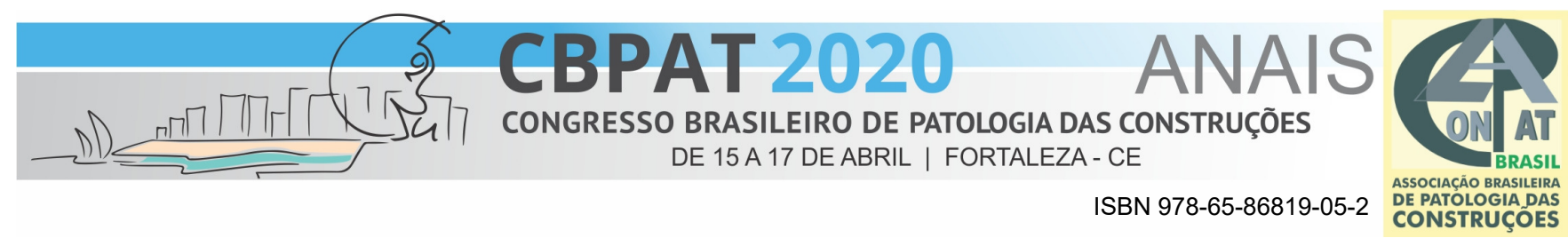

Como solução, indica-se escarificar manualmente, retirando materiais soltos ou segregados, até atingir o concreto são, remover a corrosão das armaduras existentes, limpar as superfícies através de jateamento com água com pressão e aplicar argamassa polimérica à base cimento.

\section{CONSIDERAÇÕES FINAIS}

Este trabalho apresentou seis casos de fissuração do concreto em travessa de apoio de pontes em concreto, onde se relataram os problemas encontrados, as causas da fissuração e as possíveis soluções para estes casos.

As causas de fissuração do concreto relataram foram relacionadas à corrosão das armaduras internas pela entrada de agentes agressivos no concreto ou pela corrente elétrica de fuga, e ao recalque de apoio das travessas.

Verificou-se neste trabalho que, após verificação analítica, a maioria das causas de fissuração se deve a falhas na execução e no projeto, detalhamento e dimensionamento desta travessa de apoio.

A falta de cuidados especiais no projeto e na construção de obras em ambientes agressivos ao concreto, como ambiente marinho e regiões com sulfatos de origem industrial, tem gerado cada vez mais corrosão nas armaduras das estruturas de concreto.

\section{REFERÊNCIAS}

APPLETON, J., SOUZA, R. H. F. Durabilidade das Estruturas de Betão Armado. IST, Lisboa, 1986.

ASSOCIAÇÃO BRASILEIRA DE NORMAS TÉCNICAS. NBR 6118: Projeto de estruturas de concreto Procedimento. Rio de Janeiro, 2014.

CARMONA FILHO, A., CARMONA, T. Fissuração nas estruturas de concreto. Boletim técnico n. 3. Asociación Latinoamericana de Control de Calidad, Patología y Recuperación de la Construcción - ALCONPAT Int, 2013.

CARNEIRO, L. A. V. Reforço à flexão e ao cisalhamento de vigas de concreto armado. 1998. 196 p. Dissertação (Mestrado em Engenharia Civi) - COPPE/UFRJ, Programa de Engenharia Civil, Rio de Janeiro, Brasil, 1998.

THOMAZ, E. C. S. Fissuração: Casos Reais. Disponível em <http://aquarius.ime.eb.br/ webde2/prof/ethomaz/. Acesso em: Nov 2017. 